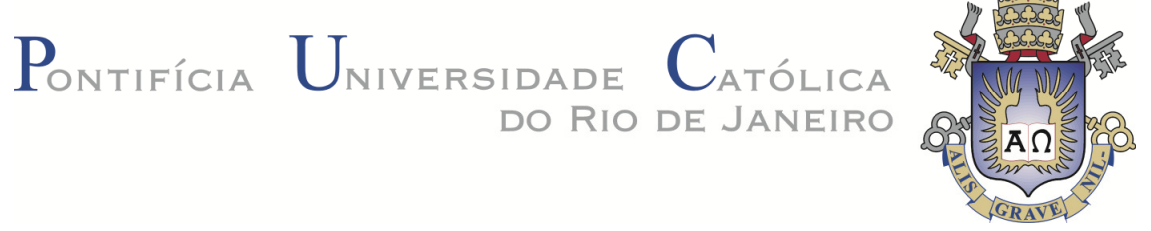

Geraldine Cássia Moniz de Souza Tonoli

Desenvolvimento Econômico Local: O Café das Montanhas Capixabas no Mercado Internacional

Dissertação de Mestrado (Opção profissional)

Dissertação apresentada como requisito parcial para obtenção do título de Mestre pelo Programa de Pós-Graduação em Administração de Empresas da PUC-Rio.

Orientador: Prof. Jorge Ferreira da Silva

Rio de Janeiro

Abril de 2014 
Pontifícia Universidade C $_{\text {atólica }}$

\title{
Desenvolvimento Econômico Local: O Café das Montanhas Capixabas no Mercado Internacional
}

Dissertação apresentada como requisito parcial para obtenção do grau de Mestre pelo Programa de PósGraduação em Administração de Empresas da PUC-Rio. Aprovada pela Comissão Examinadora abaixo assinada.

\author{
Prof. Jorge Ferreira da Silva \\ Orientador \\ Departamento de Administração - PUC-Rio
}

Prof ${ }^{a}$. Angela Maria Cavalcanti da Rocha

Departamento de Administração - PUC-Rio

Prof. Renato Dourado Cotta de Mello

UFRJ

Profa. Mônica Herz

Vice-Decana de Pós-Graduação do CCS - PUC-Rio

Rio de Janeiro, 14 de abril de 2014 
Todos os direitos reservados. É proibida a reprodução total ou parcial do trabalho sem autorização da universidade, da autora e do orientador.

\section{Geraldine Cássia Moniz de Souza Tonoli}

Graduou-se em Ciências Sociais na UERJ (Universidade do Estado do Rio de Janeiro) em 2001. Concluiu o curso de especialização em Marketing na Universidade Cândido Mendes em 2010 e de Gestão de Negócios no IAG - PUC-Rio, em 2011.

Ficha Catalográfica

Tonoli, Geraldine Cássia Moniz de Souza

Desenvolvimento econômico local: o café das montanhas capixabas no mercado internacional / Geraldine Cássia Moniz de Souza Tonoli ; orientador: Jorge Ferreira da Silva. - 2014.

65 f. : il. (color.) ; $30 \mathrm{~cm}$

Dissertação (mestrado)-Pontifícia Universidade Católica do Rio de Janeiro, Departamento de Administração, 2014.

Inclui bibliografia

1. Administração - Teses. 2. Cafés especiais. 3. Exportação. 4. Estratégia. 5. Internacionalização. 6. Cluster industrial. 7. Espírito Santo. I. Silva, Jorge Ferreira da. II. Pontifícia Universidade Católica do Rio de Janeiro. Departamento de Administração. III. Título. 
Ao França (in memorian), com meu imensurável carinho e eterna saudade. 


\section{Agradecimentos}

À minha mãe, por todo incentivo, ajuda e, sobretudo, pela incontestável paciência.

Ao meu pai, que me ensinouque é preciso persistir sempre, mesmo quando muitos não acreditam em nós.

Ao meu orientador, Professor Jorge Ferreira, pelo estímulo, parceria, paciência, aconselhamentos e bom humor desde o primeiro momento em que me tornei sua aluna.

Ao professor Jorge Carneiro, pelo apoio durante todo o curso de mestrado.

Aos demais professores do IAG, pelos ensinamentos.

Aos funcionários do IAG, pela atenção, presteza e dedicação.

Aos meus companheiros de curso, pelos inestimáveis debates que tanto contribuíram para meu crescimento acadêmico e profissional.

Aos meus amigos, pelo carinho e apoio.

À Dra. Rosa Kalmman, que não desistiu de mim.

Aos senhores Henrique Sloper Araújo, Evair Vieira de Melo, Pedro Carnielli, Rafael Marques e Eduardo Melo, pelas entrevistas que tanto contribuíram para essa dissertação. 


\section{Resumo}

Tonoli, Geraldine Cássia Moniz de Souza; Silva, Jorge Ferreira da. Desenvolvimento econômico local: o café das montanhas capixabas no mercado internacional. Rio de Janeiro, 2014. 65p. Dissertação de Mestrado - Departamento de Administração, Pontifícia Universidade Católica do Rio de Janeiro.

O presente trabalho teve por objetivo discutir as características do sistema produtivo de cafés especiais da região serrana do estado do Espírito Santo, a adoção do modelo da exportação como estratégia de negócio das empresas incumbentes e a dinâmica da difusão de conhecimento intra-cluster. Para tanto, os principais conceitos teóricos de clusters industriais, de difusão e adoção de inovações intra-rede e internacionalização de empresas que compõem um mesmo arranjo produtivo são apresentados no capítulo dois. A pesquisa caracterizou-se como exploratório-descritiva. Tratou-se, também, de uma pesquisa qualitativa, ao valer-se de um estudo de caso. Dados primários e secundários foram utilizados para a realização da pesquisa, e para a obtenção de dados primários, realizaram-se entrevistas semiestruturadas. Das informações coletadas, foi possível identificar características que classificariam o sistema produtivo estudado segundo alguns modelos apresentados no segundo capítulo. Foram consignadas recomendações de novas ações estratégicas que poderiam ter um impacto positivo sobre o desempenho das empresas incumbentes. Finalmente, sugestões para trabalhos futuros foram apresentadas.

\section{Palavras-chave}

Cafés especiais; exportação; estratégia; internacionalização; clusterindustrial; Espírito Santo. 


\section{Abstract}

Tonoli, Geraldine Cássia Moniz de Souza; Silva, Jorge Ferreira da. (Advisor) Local Economic Development: Coffee of Espírito Santo's highland in the international market. Rio de Janeiro, 2014. 65p. MSc. Dissertation - Departamento de Administração, Pontifícia Universidade Católica do Rio de Janeiro.

This paper aimed to discuss the characteristics of the specialty coffee cluster from the mountainous region of the state of Espírito Santo, the adoption of the model of exporting as business strategy and the dynamics of knowledge dissemination intra-cluster. Accordingly, the main theoretical concepts of industrial clusters, diffusion and adoption of innovations within cluster and internationalization of firms of a same industry are presented in chapter two. This research was characterized as exploratory and descriptive. Also, it was a qualitative research, as the analysis of a case study was performed. Primary and secondary data were used for the research, and to obtain primary data, semistructured interviews were conducted. With the information collected, it was possible to identify characteristics that classify the production system studied according to some models presented. Recommendations were assigned as new strategic actions which could have a positive impact on performance of incumbent firms.Finally, suggestions for future work were presented.

\section{Keywords}

Specialty coffees; exporting strategy; internationalization; industrial cluster; state of Espírito Santo. 


\section{Sumário}

$\begin{array}{ll}\text { 1. Introdução } & 14\end{array}$

$\begin{array}{lll}1.1 & \text { Problema de Pesquisa } & 14\end{array}$

1.2 Objetivo 16

$\begin{array}{lll}1.3 & \text { Objetivos Secundários } & 17\end{array}$

1.4 Delimitações do Estudo 17

1.5 Relevância do Estudo 18

2. Referencial Teórico 20

2.1 Taxonomia e Tipologia de Clusters Industriais 20

2.2 Redes de Relacionamento e a Difusão e Adoção de 26 Inovações em um mesmo cluster industrial

2.3 Internacionalização de Pequenas e Médias Empresas que 28 compõem um mesmo cluster industrial

3. Metodologia de Pesquisa 31

$\begin{array}{lll}3.1 & \text { Delineamento do Estudo } & 31\end{array}$

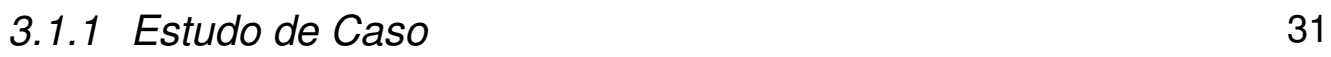

3.1.2 Tipo de Pesquisa: Exploratório-Descritivo 32

3.1.3 Abordagem Qualitativa 32

3.2 A Seleção dos Entrevistados 34

3.3 Fontes e Coleta de Dados 34

3.3.1 Dados Primários 34

3.3.2 Dados Secundários $\quad 35$

3.4 A Análise dos Dados 35

4. Apresentação e Análise dos Dados 36

4.1 O Mercado de Café 36

4.1.1 O Mercado de Café no Brasil 36

4.1.2 O Mercado Internacional de Café 37

4.1.3 O Mercado de Cafés Especiais $\quad 40$

4.2 Caracterização do Polo Cafeeiro da Serra do Espírito Santo 43

4.2.1 Breve Histórico da Cafeicultura na Região 44 
$\begin{array}{lll}4.3 & \text { Os Dados de Exportação } & 47\end{array}$

4.4 O Modelo de Exportação como Inovação 50

4.5 O Modo de Difusão da Inovação e os Agentes Externos 52

5. Conclusão 56

6. Sugestões para futuros trabalhos 59

$\begin{array}{ll}7 . & 60\end{array}$ 


\section{Lista de Figuras}

Figura 1: Mapa do Estado do Espírito Santo

Divisão em Microrregiões de Gestão Administrativa................................43

Figura 2: Mapa da Região das Montanhas Capixabas...........................44

Figura 3: Rede Institucional da Cafeicultura Capixaba

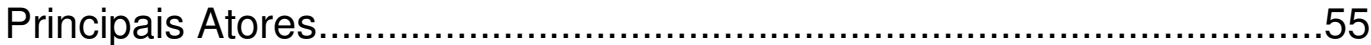




\section{Lista de Quadros}

Quadro 1: Principais respostas das teorias / Questões básicas do processo de internacionalização...............................................................30

Quadro 2: Produção Mundial de Café - Anos-safra 2000 a 2012............40 


\section{Lista de Tabelas}

Tabela 1: Consumo em mercados tradicionais

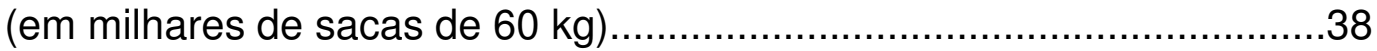

Tabela 2: Exportações dos Principais Países Produtores (em milhares de sacas de $60 \mathrm{~kg}$ ).

Tabela 3: Exportações Brasileiras de Café entre Janeiro e Março de

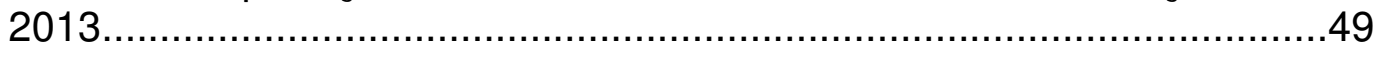

Tabela 4: Exportações Brasileiras de Café Verde (Principais Países Importadores). 
Manoel de Barros 